\title{
Orientações para Realização de Exames de Ressonância Magnética Nuclear em Pacientes com Dispositivos Eletrônicos Cardíacos
}

\author{
Guidelines for Performing Nuclear Magnetic Resonance Imaging \\ Examinations in Patients with Cardiac Electronic Devices
}

Antonio Vitor Moraes Junior ${ }^{1,2}$, Bruno Pereira Valdigem ${ }^{1,2^{*}}$, Cecilia Monteiro Boya Barcelos ${ }^{1,2}$, Celso Salgado de Melo ${ }^{1,2}$, Wilson Lopes Pereira ${ }^{1,2}$, Hilton Muniz Leão Filho3, Marco Antônio Rocha Mello $^{3}$, Cyro Antônio Fonseca Junior ${ }^{3}$, Fernando Eduardo Nunes Mariz ${ }^{3}$, Marcelo Rodrigues de Abreu $^{3}$, Patrícia Prando Cardia ${ }^{3}$, Paulo Roberto Vieira de Andrade ${ }^{3}$, Simone Kodlulovich Renha ${ }^{3}$, Alexander dal Forno ${ }^{4}$, Andre Luiz Buchele D ' Avila ${ }^{4}$, Ricardo Alkmin Teixeira ${ }^{4}$, Veridiana Silva de Andrade ${ }^{4}$

\section{INTRODUÇÃO}

Estima-se que até 75\% dos pacientes com dispositivos cardíacos eletrônicos implantáveis (DCEIs) terão indicação de exame de ressonância nuclear magnética (RNM) ao longo da vida. Pelas características dos dispositivos, esses foram excluídos historicamente do rol de pacientes considerados elegíveis ao exame.

O DCEI é composto por cabo-eletrodos e gerador. Cada cabo-eletrodo é um conector metálico multifilamentar espiral que liga o gerador ao músculo cardíaco. O gerador, por sua vez, é composto de bateria, circuitos e conector para os cabo-eletrodos. A função dos cabo-eletrodos é conduzir impulsos elétricos com energia mínima suficiente para iniciar um impulso elétrico cardíaco (onda p ou QRS). Outra função essencial dos cabo-eletrodos é transmitir informação elétrica adquirida no miocárdio (eletrograma intracavitário) até o gerador, ou seja, sentir o ritmo elétrico nativo do paciente, evitando estimulação desnecessária.

O gerador fica localizado geralmente em espaço infraclavicular direito ou esquerdo (ou menos frequentemente na região lateral do tórax ou abdome). Tem a função de interpretar os estímulos oriundos dos cabo-eletrodos e gerar impulso elétrico por meio de corrente elétrica entre o miocárdio e o gerador (utilizando os cabo-eletrodos como condutor). Nesse residem a bateria necessária para o impulso (com durabilidade geralmente entre sete e 15 anos) e os circuitos programáveis que permitem frequência mínima, elevação de frequência dependente de movimento, integração entre cabo-eletrodos localizados em diversas câmaras cardíacas, entre outros. Em casos excepcionais, como em crianças, o gerador pode ser posicionado no abdome e cabos-eletrodos geralmente transvenosos e, eventualmente, epimiocárdicos. Sistemas comgerador implantado diretamente dentro do coração - leadless pacemaker ou com desfibrilador implantável (CDI) subcutâneo estão disponíveis para uso em casos selecionados. O campo magnético gerado pela RNM pode ser interpretado pelo DCEI como sinal elétrico cardíaco anormal (QRS ou onda p) e criar interferência que cause um dos seguintes comportamentos:

1.Sociedade Brasileira de Cirurgia Cardiovascular - Departamento de Estimulação Cardíaca Artificial - São Paulo/SP - Brasil

2.Associação Brasileira de Arritmia, Eletrofisiologia e Estimulação Cardíaca Artificial - São Paulo/SP - Brasil

3.Colégio Brasileiro de Radiologia e Diagnóstico por Imagem - São Paulo/SP-Brasil

4.Sociedade Brasileira de Arritmias Cardíacas - São Paulo/SP-Brasil

*Autor correspondente: valdigem@gmail.com

ORCID: Valdigem BP (iD https://orcid.org/0000-0003-0676-2033 
- Deflagrar estímulos cardíacos artificiais com frequência elevada;

- Inibição dos estímulos cardíacos;

- Dano aos cabo-eletrodos, ao gerador ou aquecimento do sistema;

- Modificação de parâmetros de estimulação forçada (reset);

- Deflagração de choques inapropriados (quando se tratar do cardiodesfibrilador interno).

Apesar do receio inicial, a movimentação do dispositivo e a torção dos cabo-eletrodos não se mostraram evidentes pela aderência dos tecidos ao subcutâneo.

O aquecimento do sistema (causando dano aos componentes e lesão ao miocárdio em volta do cabo-eletrodo) foi comprovado para cabo-eletrodos não condicionais. Esse aquecimento pode levar a aumento do limiar necessário para a estimulação miocárdica e desconforto do paciente.

Todos os DCEI a serem submetidos à RNM devem ser reprogramados antes e após o exame. Alguns dispositivos mais recentes têm capacidade de deteç̧ão do campo magnético da RNM quando ativados por um período predeterminado que tornam a programação adequada quando o paciente se encontra dentro da sala do aparelho (zona 4). A maioria, no entanto, deve ser reprogramada para o modo assíncrono ou modo adequado o mais tardiamente possível e retornar à programação original após o término do exame no menor espaço de tempo julgado adequado pelo médico responsável pelo acompanhamento do paciente com DCEI. Essa orientação se fundamenta no risco potencial de estimulação assíncrona, competindo com o ritmo próprio do paciente e sendo potencialmente arritmogênica em marcapassos. Pacientes com cardiodesfibriladores não devem sair de ambiente supervisionado sem a adequada proteção de terapias antitaquicardia.

\section{DEFINIÇÕES DE DISPOSITIVOS}

- Marcapassos: dispositivo que tem função de estimulação e sensibilidade. O marcapasso permite garantir a frequência mínima estimulada do paciente. A programação é descrita por letras (Tabela 1).

- Ressincronizadores: também chamados marcapassos ou estimuladores multissítio, são dispositivos que permitem estimulação simultânea de ventrículo esquerdo (VE) através de cabo-eletrodo posicionado em veia epicárdica tributária do seio coronariano venoso. Pode ou não estar associado à função desfibriladora e, em caso positivo, é chamado desfibrilador multissítio. Os pacientes com ressincronizadores cardíacos têm doença cardíaca estrutural importante e fração de ejeção de VE comprometida (geralmente inferior a 35\%). O cabo-eletrodo de VE é posicionado em veia epicárdica tributária do seio coronariano venoso. Eventualmente o cabo-eletrodo do VE pode ser implantado por acesso epimiocárdico.

- Cardiodesfibriladores (CDI): DCEI com função de estimulação idêntica ao marcapasso. Também tem capacitor que permite ao dispositivo liberação de choques com energia alta. A função desses é controlar taquicardias ventriculares ou fibrilação ventricular e geralmente estão implantados em pacientes com graus diferentes de disfunção ventricular ou em risco maior de parada cardiorrespiratória.

- Monitores de eventos: Dispositivos entre 3 e $6 \mathrm{~cm}$ posicionados no tórax anterior, subcutâneos. Sua função é monitoramento prolongado de arritmias cardíacas. Todos os monitores de eventos disponíveis atualmente são compatíveis com RNM. Recomenda-se, a critério do médico, a avaliação dos dados antes do exame, pelo risco de perda das informações coletadas até o momento ou mesmo a supressão dessas pela aquisição dos artefatos do campo magnético.

- Dispositivos condicionais: são DCEI aos quais a exposição ao campo magnético não apresenta risco ao paciente. Esses são DCEI que contêm apenas cabo-eletrodos descritos pelo fabricante como condicionais, conectados a geradores também descritos pelo fabricante como condicionais e que não preenchem os critérios de exclusão. Os cabo-eletrodos e geradores devem ser do mesmo fabricante. A utilização de cabo-eletrodos e geradores de fabricantes diferentes pode não ter a garantia em caso de dano ao sistema.

- Dispositivos não condicionais: aqueles que não foram testados de forma ampla e/ou que não têm a garantia do fabricante contra danos potenciais causados pelo ambiente da RNM (Tabela 2). 
Tabela 1. Modos de programação de marcapasso para a realização de ressonância magnética nuclear.

\begin{tabular}{cccc}
\hline Câmara estimulada & Câmara sentida & Resposta ao evento sentido & Frequência adaptativa \\
\hline $\mathrm{O}=$ Nenhuma & $\mathrm{O}=$ Nenhuma & $\mathrm{O}=$ Nenhuma & $\mathrm{R}=$ Resposta de \\
$\mathrm{A}=$ Átrio & $\mathrm{A}=$ Átrio & $\mathrm{I}=$ Inibido & frequência ligada \\
$V=$ Ventrículo & $V=$ Ventrículo & $\mathrm{T}=$ Deflagrado & $\mathrm{D}=$ As duas \\
$\mathrm{D}=$ Átrio e ventrículo & $\mathrm{D}=$ Átrio e ventrículo & \\
\hline
\end{tabular}

Tabela 2. Checklist para a realização de ressonância nuclear magnética (RNM) em pacientes com dispositivos eletrônicos cardíacos.

\section{Antes do exame}

Autorização do médico estimulista informando (necessária a checagem da equipe responsável pela RNM):

- Se o dispositivo é condicional;

- Se está com as funções auto detect ou similares programada;

- Se a programação será feita por membro de sua equipe/por membro do serviço de radiologia imediatamente antes da RNM e após o término do exame;

- Se o paciente está apto a realizar o procedimento sem a necessidade de reprogramação.

- Caso atenda aos protocolos institucionais

- Checar se há profissional disponível no local para reprogramação, quando necessário (não condicionais ou não programados);

- Checar se há equipe apta a atendimento de parada cardiorrespiratória (PCR);

- Checar se há material disponível para atendimento de PCR.

\section{Durante o exame}

- Checar se há monitorização de ritmo e saturação eficaz.

- Após o exame

- Checar sinais vitais do paciente;

- Checar se o dispositivo foi reprogramado com o aval do médico responsável pelo procedimento;

- Confirmar com médico responsável a segurança da alta do paciente.

\section{PARÂMETROS MÍNIMOS DE SEGURANÇA}

Os parâmetros mínimos de segurança para pacientes com DCEI na sala de RNM são:

1. Monitorização de ritmo cardíaco (preferencialmente por eletrocardiograma) e saturação em tempo real durante todo o exame;

2. Presença de médico e equipe aptos a atendimento de parada cardiorrespiratória (PCR) na seção de radiologia (imediatamente fora da zona 4, também conhecida como sala de RNM);

3. Disponibilidade de material para atendimento de PCR imediatamente fora da zona 4, de acordo com as diretrizes vigentes de Advanced Cardiovascular Life Support (ACLS);

4. Sugere-se a realização desses procedimentos em âmbito hospitalar ou em clínica que tenha os parâmetros $1,2 \mathrm{e}$ 3 e capacidade de remoção do paciente com segurança para unidade de terapia intensiva em caso de necessidade;

5. Dispor de protocolo operacional padrão institucional de fácil acesso a todos os membros do laboratório.

\section{ORIENTAÇÕES ESPECÍFICAS PARA OS DIFERENTES DISPOSITIVOS Estimuladores Condicionais}

Os dispositivos implantáveis condicionais chegaram ao Brasil em 2012. Os fabricantes desenvolveram cabo-eletrodos e geradores que permitem a realização de exames de ressonância magnética inicialmente com zona de exclusão (evitando 
tórax, região cervical e abdome superior), sendo posteriormente autorizados para todo o corpo. Outros modelos foram desenvolvidos com tecnologias semelhantes.

A carteira do paciente com marcapasso contém o modelo dos cabo-eletrodos e do gerador do paciente com informações sobre compatibilidade com ressonância. A lista completa atualizada de cabo-eletrodos e geradores condicionais está disponível no site da Associação Brasileira de Arritmia, Eletrofisiologia e Estimulação Cardíaca Artificial (ABEC) (https://abecdeca.org.br/medico).

Os DCEI precisam, no entanto, ser reprogramados previamente à exposição ao campo magnético. O objetivo dessa reprogramação é tornar o DCEI indiferente ao campo magnético (modo assíncrono) e realizar outras modificações, como elevação da energia de estimulação. A reprogramação também deve avaliar limiares de comando e carga restante da bateria para aferir a segurança da exposição do paciente ao campo magnético. Idealmente a bateria não deve ter menos de $30 \%$ da carga e os limiares de comando não devem ser elevados previamente ao exame, apesar de não serem contraindicações absolutas ao procedimento.

Os parâmetros de 1,5 T, gradiente slew rate < ou = a $200 \mathrm{~T} / \mathrm{m} / \mathrm{s}$ e SAR máximo < ou = a $2 \mathrm{~W} / \mathrm{kg}$ permitem segurança em todos os dispositivos condicionais independentemente da região de interesse. Alguns dispositivos já permitem $3 \mathrm{~T}$ e isso pode ser verificado caso seja do interesse do paciente e do médico responsável pela aquisição das imagens.

\section{Cardiodesfibriladores Condicionais}

Os cardiodesfibriladores condicionais também demonstram segurança comprovada à exposição do paciente ao ambiente magnético, assim como necessitam de reprogramação prévia ao exame e de retorno aos parâmetros originais após seu término desse. Além da indiferença ao campo magnético (modo assíncrono), a reprogramação visa inibir sua detecção inapropriada e sua interpretação como taquicardia ou arritmia ventricular.

Isso remove a proteção antitaquicardia inerente ao dispositivo durante a programação específica para ressonância. A inibição da detecção de taquicardias impede que o paciente receba choques durante o exame.

Assim, nesse contexto, se o paciente apresentar espontaneamente taquicardia ventricular sustentada, o tratamento deverá ser idêntico ao de pacientes que não têm CDI, de acordo com as diretrizes vigentes do ACLS.

\section{Dispositivos Não Condicionais}

Existe ampla literatura sobre séries de casos de pacientes com DCEI não condicionais submetidos à RNM sem eventos adversos. Diversos estudos estão em andamento para validar o uso de RNM nesses dispositivos como rotina.

Sempre que a RNM for o método diagnóstico essencial não substituível ou necessário em caráter emergencial, a realização do exame não deve ser evitada pela presença do DCEI. Idealmente deveria ser realizada em ambiente que atenda às condições mínimas sugeridas neste documento. A maioria dos dispositivos submetidos à RNM com 1,5 T tolerou o procedimento, bem como exames com duração inferior a 40 minutos. Apesar da ausência de estudos randomizados, sugere-se a manutenção de parâmetros de segurança com exames de curta duração e campo igual ou inferior a 1,5 T.

A reprogramação da funcionalidade do DCEI não condicional para os parâmetros "compatíveis com a ressonância" pode ser realizada em qualquer DCEI ainda que o fabricante não garanta a segurança dos componentes em caso de danos, tais como: redução ou supressão da estimulação cardíaca, mudança súbita de modo, aquecimento dos circuitos e cabo-eletrodos, além de falha na captura durante o procedimento ou tardiamente.

Em caso de necessidade de realização de RNM em DCEI não condicional, sugere-se a presença de médico apto para avaliação do funcionamento e reprogramação do dispositivo no ambiente da radiologia, com reavaliação da funcionalidade do DCEI ao término do procedimento e antes da alta do ambiente supervisionado. Também deve ser prevista a necessidade de estimulação cardíaca temporária em caso de disfunção do dispositivo.

\section{CRITÉRIOS DE EXCLUSÃO}

Os critérios de exclusão devem ser considerados e discutidos com o médico assistente. Em caso de pacientes com necessidade absoluta do exame na vigência de critérios de exclusão, o risco de eventos potencialmente fatais deve ser discutido 
com o médico assistente e com o paciente. O DCEI deve ser considerado não condicional e tratado como tal quando (ver a descrição em dispositivos não condicionais):

- Presença de cabo-eletrodos abandonados ou não condicionais;

- Presença de cabo-eletrodos epicárdicos;

- Implante há menos de seis semanas;

- Implantes não torácicos;

- Crianças.

\section{LITERATURA ADICIONAL SUGERIDA}

Indik JH, Gimbel JR, Abe H, et al. HRS expert consensus statement on magnetic resonance imaging and radiation exposure in patients with cardiovascular implantable electronic devices Heart Rhythm. 2017;14(7):e97-e153. https://doi.org/10.1016/j.hrthm.2017.04.025

Mayo Foundation for Medical Education and Research. New protocols allow for MRI in selected patients with pacemakers [Internet]. Mayo Clinic; Disponível em: https://www.mayoclinic.org/medical-professionals/clinical-updates/cardiovascular/new-protocolsallow-mri-selected-pacemaker-patients

Mattei E, Gentili G, Censi F, et al. Impact of capped and uncapped abandoned leads on the heating of an MR-conditional pacemaker implant. Magn Reson Med. 2015;73(1):390-400. https://doi.org/10.1002/mrm.25106

Boilson BA, Wokhlu A, Acker NG, et al. Safety of magnetic resonance imaging in patients with permanent pacemakers: a collaborative clinical approach. J Interv Card Electrophysiol. 2012;33(1):59-67. https://doi.org/10.1007/s10840-011-9615-8

Burke PT, Ghanbari H, Alexander PB, et al. A protocol for patients with cardiovascular implantable devices undergoing magnetic resonance imaging (MRI): should defibrillation threshold testing be performed post-(MRI). J Interv Card Electrophysiol. 2010;28(1):5966. https://doi.org/10.1007/s10840-009-9463-y 